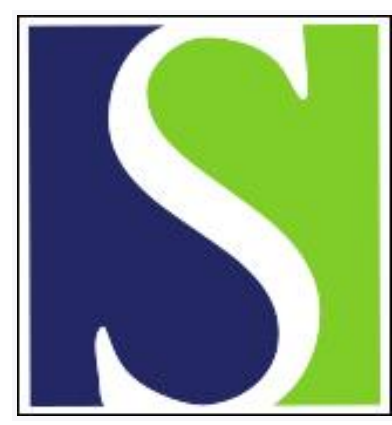

Scand J Work Environ Health 2000;26(4):322-330

https://doi.org/10.5271/sjweh.549

Issue date: Aug 2000

Human cancer risk and exposure to 1,3-butadiene - a tale of mice and men

by Stayner LT, Dankovic DA, Smith RJ, Gilbert SJ, Bailer AJ

Key terms: epidemiology; leukemia; risk assessment; toxicology

This article in PubMed: www.ncbi.nlm.nih.gov/pubmed/10994798






\title{
Human cancer risk and exposure to 1,3-butadiene - a tale of mice and men
}

\author{
by Leslie T Stayner, PhD, ${ }^{1}$ David A Dankovic, PhD, ${ }^{1}$ Randall J Smith, MA, ${ }^{1}$ Stephen J Gilbert, MS, ${ }^{1}$ A
} John Bailer, $P h D^{1,2}$

\begin{abstract}
Stayner LT, Dankovic DA, Smith RJ, Gilbert SJ, Bailer AJ. Human cancer risk and exposure to 1,3-butadiene - a tale of mice and men. Scand J Work Environ Health 2000;26(4):322-330.

Objectives The purpose of this study was to evaluate empirically the relevance of animal-bioassay-based models for predicting human risks from exposure to 1,3-butadiene (BD) using epidemiologic data.

Methods Relative-risk results obtained with a regression model in a recent epidemiologic study were used to estimate leukemia risk for occupational and environmental exposures to BD and to compare these estimates with those previously derived from an analysis of animal bioassay data.

Results The estimates of risk were found to be highly dependent on the model used when low levels of exposure were evaluated that are of environmental concern, but not at the levels of occupational concern. For example, at the level ( 1 part per million) of the recently revised standard of the Occupational Safety and Health Administration in the United States the estimates of lifetime excess risk ranged from 1 to 8 per 1000 workers. The range of the risk estimates derived from the epidemiologic models was remarkably similar to the range of risk estimates for occupational exposures ( 1 to 9 per thousand) previously developed by Dankovic et al in 1993 from an analysis of a mouse bioassay study for lymphocytic lymphoma.

Conclusions Results for BD seem to provide another example of a high degree of concordance between the risk predictions from models of toxicologic and epidemiologic data, particularly at occupational levels of exposure.
\end{abstract}

Key terms epidemiology, leukemia, risk assessment, toxicology.

The use of animal bioassay data for the characterization of human risks and the determination of regulatory policies in the United States (US) is controversial. Ames \& Gold (1-3) have argued that the high exposure levels used in experimental studies frequently induce tumors by mechanisms that are not operative at the lower exposures generally experienced by humans. A Science editorial (4) has even gone so far as to state that "The standard carcinogen tests that use rodents are an obsolescent relic of the ignorance of past decades". Others have defended the use of animal bioassays with equal vigor $(5-7)$.

A recent debate over the potential carcinogenicity of 1,3-butadiene (BD) exemplifies the current arguments surrounding the relevance of animal bioassay data for predicting human cancer risks (8-11). The mechanistic arguments concerning this issue have been reviewed recently by Melnick \& Kohn (12).

Although the theoretical arguments for and against the use of animal bioassay data for human risk assessment may continue, we believe that the science of risk assessment will be well served by the development, to the extent possible, of empirical data comparing the risks observed in humans to those estimated from bioassays. In this paper we have developed estimates of leukemia risk based on a recent analysis of a cohort study of workers exposed to BD and then compared these risk predictions with those previously developed on the basis of animal bioassay data.

\section{Materials and methods}

The recently reported findings from a retrospective cohort mortality study conducted by researchers at the University of Alabama (UAB) provided the primary data for this analysis (13-14). This study included 17964 men employed for at least 1 year between 1943 and 1991 at 8 North American plants that made styrene-butadiene rubber.

The investigators developed a job-exposure matrix for $\mathrm{BD}$, styrene, and benzene on the basis of industrial

1 Risk Evaluation Branch, Education and Information Division, National Institute for Occupational Safety and Health, Cincinnati, Ohio, United States.

2 Department of Mathematics and Statistics, Miami University, Oxford, Ohio, United States.

Reprint requests to: Dr LT Stayner, National Institute for Occupational Safety and Health C15, 4676 Columbia Parkway, Cincinnati, Ohio 45226, United States. [E-mail: 1ts2@cdc.gov] 
hygiene data, which contained estimates of the average daily exposure (in parts per million based on an 8-hour time-weighted average), and the number of annual peaks (defined as $\geq 100 \mathrm{ppm}$ for $\mathrm{BD}$ and $\geq 50 \mathrm{ppm}$ for styrene) for each area and job code for each study year. The investigators were then able to estimate cumulative exposure estimates (ppm · years and peak · years) by linking the job-exposure matrix with the subject's work histories.

The results from Poisson regression (15) exposureresponse analyses of this study were presented in a report (henceforth referred to as the UAB study) to the In ternational Institute of Synthetic Rubber Workers by the UAB researchers (Delzell E, Sathiakumar N, Macaluso M, Hovinga M, Larson R, Barbone F et al. A follow-up study of synthetic rubber workers. Report submitted to The International Institute of Synthetic Rubber Workers, October 2, 1995). The models controlled for the potentially confounding effects of age (categories of $40-49$, $50-59,60-69,70-79, \geq 80$ years), time since hire (categories of $10-19,20-29, \geq 30$ years), calendar period (categories of 1950-1959, 1960-1969, 1970-1979, 1980 - 1989, 1990-1991), and race (black, other). The plant was considered a possible confounder but was dropped from the final models because it did not affect the estimated parameters for BD or styrene. Few subjects were exposed to benzene, and benzene did not appear to confound the relationship between the $\mathrm{BD}$ or styrene exposure and leukemia mortality. Hence the model results presented in the report did not control for benzene exposure.

Different functional forms of the relationship between the relative rate (RR) and measures of exposure were evaluated in the UAB analysis, including the following: (i) $\log$-linear $\mathrm{RR}=\mathrm{e}^{\beta \mathrm{X}}$; (ii) power: $\mathrm{RR}=\mathrm{e}^{\beta[\ln (1+\mathrm{X})]}=(1+$ $X)^{\beta}$; (iii) linear: $R R=1+\beta X$; (iv) polynomial: $R R=1+$ $\beta_{1} X+\beta_{2} X^{2}+\ldots ;(v)$ square root: $R R=1+\beta_{1} X^{1 / 2}$, where $\mathrm{X}$ represents $\mathrm{BD}$ or styrene exposures and the $\beta$ values represent the model parameters. Exposure $(\mathrm{X})$ was either coded as a set of categorical variables or as a continuous variable using the midpoints of the exposure categories. Note that the given models correspond to a case in which $\mathrm{X}$ is continuous. Their models also included variables to adjust for the potentially confounding effects of age, calendar period, years since hire, and race.

The Poisson regression analyses revealed a positive exposure-response relationship between cumulative exposure to BD or styrene and leukemia mortality. This relationship was evident in both of the models that represented these exposures as categorical variables and in models in which exposure was represented using continuous variables as already described. The BD and styrene exposures among the exposed subjects were found to be moderately correlated (Spearman's rank correlation, $\mathrm{r}=0.53$ ). The relationship between cumulative BD exposure and leukemia mortality appeared to be independent of the styrene exposure, and it was not appreciably altered by the inclusion of cumulative styrene exposure in the model. On the other hand, the relationship between cumulative styrene exposure and leukemia mortality was weakened and irregular when cumulative BD exposure was included in the model. These findings suggest that cumulative $\mathrm{BD}$ exposure is a more likely explanation for the leukemia excess observed in this cohort than cumulative styrene exposure.

Analyses of peak-years (a peak exposure was defined as any exposure greater than $100 \mathrm{ppm}$ ) indicated an association between this variable and leukemia mortality even after control for cumulative exposure, but this relationship was not monotonic in the categorical regression analyses. Excluding exposures that occurred within 5 or 10 years of death (ie, lagging exposures) only slightly increased the exposure-response relationship for cumulative $\mathrm{BD}$ exposure, whereas excluding exposures within 20 years of death weakened and almost eliminated the relationship.

The regression parameter for BD exposure was found to be statistically significantly greater than $0(\mathrm{P}<0.05)$ with all of the model forms evaluated.

The power and square root models were found to provide the best fit to the data in a comparison of the model deviances. However, the difference in deviance between the various models was slight. The square root model was identified as the "best model" according to its goodness of fit and its simplicity. This model was refined into a final model (henceforth referred to as the "final square root model") by omitting styrene and race since the effect of these variables on the estimated parameter for $\mathrm{BD}$ exposure was considered to have been minimal. In addition, certain age, calendar year, and years since hire categories were collapsed for their final model for similar reasons. The relationship between cumulative $\mathrm{BD}$ exposure and leukemia mortality was highly statistically significant in the final model $(\mathrm{P}=0.002)$.

\section{Prediction of lifetime excess risk of leukemia}

The relative rate models presented in the UAB analysis were used as a basis for predicting the lifetime excess risk of leukemia mortality for varying levels of occupational and environmental exposures to BD. Lifetime risk was estimated using the relative rate estimates derived from these models and an actuarial program that takes into account the effects of competing causes of death. ${ }^{3}$ US age-specific mortality rates for males (16) were used 
to specify the leukemia and all cause background rates in the actuarial program. For estimating occupational risks, it was assumed that workers were exposed for 45 years to a constant BD concentration starting at 20 years of age and ending at 65 years of age, whereas for environmental exposures it was assumed that exposures were for the entire lifetime. Lifetime risks were computed up to 85 years of age. For estimating environmental risks, the occupational BD exposures in the epidemiologic study were converted to equivalent continuous environmental exposures by multiplying the occupational exposure estimates by a factor to account for differences in the number of days exposed per year (365/240 days) and another factor to account for differences in the amount of air inhaled per day (20/10 liters). The reported standard errors for the BD regression coefficients were used to compute the upper 1-sided $95 \%$ confidence limit for the relative rates and lifetime risks of leukemia (or the corresponding $95 \%$ lower 1-sided limit on exposure) on the basis of a normal approximation.

Consistent with the new cancer guidelines (17) of the US Environmental Protection Agency (EPA) the results from these risk assessment models were also used to estimate the "effective concentration" $\left(\mathrm{EC}_{\mathrm{p}}\right)$ and lower $95 \%$ confidence limits ( $\mathrm{LEC}_{\mathrm{p}}$ ), which is the concentration (or exposure) associated with a specified level of excess risk (p) such as $1 \%$ or $0.1 \%$. The advantage of this approach is that it restricts risk estimation to approximately the
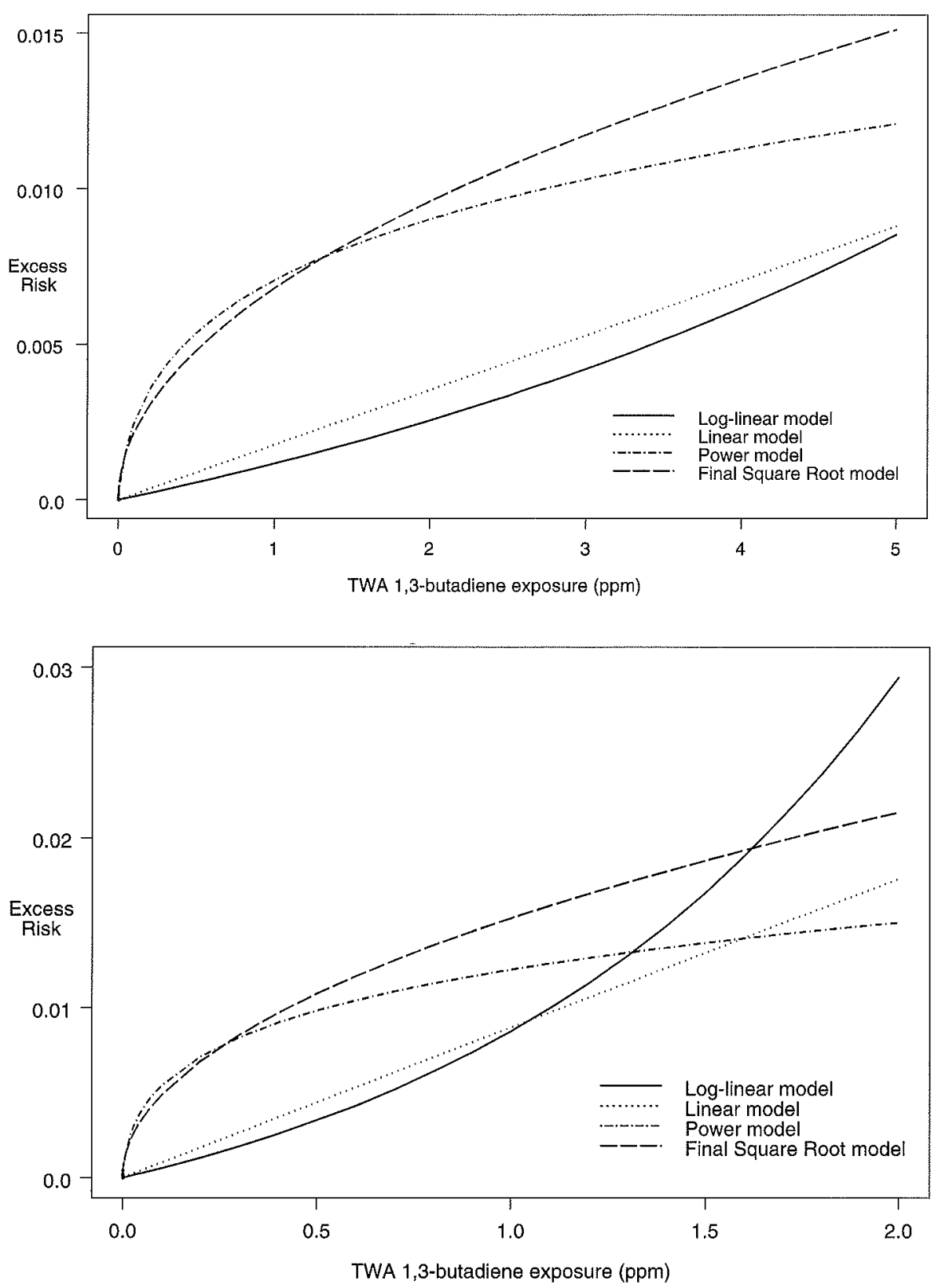

Figure 1. Excess risk for occupational exposures to 1,3-butadiene using alternative models (TWA = time-weighted average)
Figure 2. Excess risk for environmental exposure to 1,3 butadiene using alternative models. (TWA=time-weighted average) 
range of the data and thus avoids making extrapolations well beyond the data.

The risk estimates for the occupational exposures were compared with those previously derived for occupational exposures (18) based on modeling of the findings from the National Toxicology Program (NTP) studying $\mathrm{B} 6 \mathrm{C} 3 \mathrm{~F} 1$ mice exposed via inhalation to $\mathrm{BD}$.

\section{Results}

The maximum likelihood (point) estimates of the lifetime risk of leukemia in association with varying levels of occupational and environmental exposures to BD are illustrated in figures 1 and 2. Point estimates and lower $95 \%$ confidence limits for environmental and occupational exposure levels in association with specific levels of excess lifetime risk are presented in table 1. Environmental regulations are frequently targeted by the EPA to limit risks to below a 1 in a million risk level, whereas occupational standards developed by the Occupational Safety and Health Administration (OSHA) are generally targeted to limit exposures at or below a 1 in a 1000 risk level (19). It can be seen from table 1 that the results are highly model dependent for exposures corresponding to risks of environmental concern ( 1 in a million) with the estimates of exposure spanning approximately 5 orders of magnitude. In contrast, the results are between 1 and 2 orders of magnitude for exposures at risk levels of occupational concern ( 1 in a 1000). OSHA recently reduced its permissible exposure limit (PEL) from 1000 to $1 \mathrm{ppm}$ (20). These models predict that, at the revised OSHA standard of 1 ppm, the predicted risks (point estimates) would be approximately 1 to 7 per 1000 workers.

\section{Estimates of the effective concentration}

Point estimates and lower $95 \%$ confidence limits for the effective concentration ( $\mathrm{EC}_{\mathrm{p}}$ ) for environmental exposures corresponding to levels of excess risk varying from $0.1 \%$ to $10 \%$ from the alternative models are presented in table 2 and illustrated for the final square root model in figure 3. Although the new EPA guidelines emphasize the derivation of exposure levels associated with a $10 \%$ risk level, this procedure does not seem reasonable in this instance. The $10 \%$ level of risk is associated with exposure levels that are higher than most of the exposures experienced by the workers in this epidemiologic study. This problem is illustrated by the fact that a $10 \%$ risk level would correspond to a relative rate of 19 , but the leukemia standardized mortality ratios (SMR) reported in the $\mathrm{UAB}$ analysis were considerably lower. ${ }^{4}$ Hence, these considerations suggest that using a $10 \%$ risk level would be an upward extrapolation in this case. A $1 \%$ risk or even a lower (eg, $0.1 \%$ ) risk level would seem to be a more reasonable choice in this circumstance. The analogous relative rates for increased risks of $1 \%$ or $0.1 \%$ are 2.7 and 1.17 , respectively, which better correspond with the set of standardized mortality ratios reported in the UAB analysis. When a $1 \%$ risk level is used, the $\mathrm{LEC}_{1}$ from these analyses ranges from 0.06 to $0.6 \mathrm{ppm}$ depending on the relative rate model used. Using the "final" model presented in the UAB analysis would yield an $\mathrm{LEC}_{1}$ of $0.11 \mathrm{ppm}$.

Ratios that were calculated by dividing the excess risk (p) by the corresponding $\mathrm{LEC}_{\mathrm{p}}$ for each model are also presented in table 2. Each ratio is the slope of the line segment connecting the point $\left(\mathrm{LEC}_{\mathrm{p}}, \mathrm{p}\right)$ with the origin. This ratio is essentially a measure of the risk per unit of exposure under the assumption of low-dose linearity (ie, a unit risk). According to the $\mathrm{LEC}_{1}$, these ratios vary by 1 order of magnitude from 0.016 to 0.16 . If these $\mathrm{LEC}_{1}$ based ratios were used to calculate the concentration

Table 1. Estimates of maximum likelihood and the $95 \%$ lower confidence limit (95\% LCL) of environmental and occupational exposures associated with varying levels of lifetime excess risk.

\begin{tabular}{|c|c|c|c|c|}
\hline \multirow[t]{2}{*}{$\begin{array}{l}\text { Excess } \\
\text { risk }\end{array}$} & \multicolumn{2}{|c|}{$\begin{array}{l}\text { Environmental } \\
\text { exposure (ppm) }\end{array}$} & \multicolumn{2}{|c|}{$\begin{array}{c}\text { Occupational } \\
\text { exposure (ppm) }\end{array}$} \\
\hline & $\begin{array}{l}\text { Maximum } \\
\text { likelihood }\end{array}$ & $95 \% \mathrm{LCL}$ & $\begin{array}{l}\text { Maximum } \\
\text { likelihood }\end{array}$ & $95 \%$ LCL \\
\hline \multicolumn{5}{|c|}{ Log-linear $\left(R R=e^{\beta x}\right)$ model } \\
\hline $1 \mathrm{e}-6$ & $1.9 \mathrm{e}-4$ & $1.1 \mathrm{e}-4$ & $9.4 \mathrm{e}^{\mathrm{m}}$ & $5.3 e-4$ \\
\hline $1 e-5$ & $1.9 \mathrm{e}-3$ & $1.1 \mathrm{e}-3$ & $9.4 \mathrm{e}-3$ & $5.3 e-3$ \\
\hline $10-4$ & $1.9 e-2$ & $1.1 \mathrm{e}-2$ & $9.3 e-2$ & $5.3 \mathrm{e}-2$ \\
\hline $1 e-3$ & 0.17 & $9.8 \mathrm{e}-2$ & 0.87 & 0.49 \\
\hline \multicolumn{5}{|c|}{ Linear $(R R=1+\beta X)$ model } \\
\hline $1 e-6$ & $1.1 e-4$ & $5.1 e-5$ & $5.7 \mathrm{e}^{-4}$ & $2.6 e-4$ \\
\hline $1 e-5$ & $1.1 \mathrm{e}-3$ & $5.1 \mathrm{e}-4$ & $5.7 e-3$ & $2.6 \mathrm{e}-3$ \\
\hline $1 e-4$ & $1.1 e-2$ & $5.1 e-3$ & $5.7 e-2$ & $2.6 \mathrm{e}-2$ \\
\hline $1 \mathrm{e}-3$ & 0.11 & $5.1 \mathrm{e}-2$ & $5.7 e-1$ & 0.26 \\
\hline \multicolumn{5}{|c|}{ Power $\left(R R=e^{\beta[[m(1+x)]}\right)$ model } \\
\hline $1 e-6$ & $3.8 \mathrm{e}-6$ & $2.1 \mathrm{e}-6$ & $1.9 \mathrm{e}-5$ & $1.1 \mathrm{e}-5$ \\
\hline $10-5$ & $3.8 \mathrm{e}-5$ & $2.1 \mathrm{e}-5$ & $1.9 \mathrm{e}^{-4}$ & $1.1 e-4$ \\
\hline $1 e-4$ & $3.90-4$ & $2.1 \mathrm{e}-4$ & $2.0 \mathrm{e}-3$ & $1.1 \mathrm{e}-3$ \\
\hline $1 e-3$ & $5.2 e-3$ & $2.4 \mathrm{e}-3$ & $2.6 \mathrm{e}-2$ & $1.2 \mathrm{e} \sim 2$ \\
\hline \multicolumn{5}{|c|}{ Initial square root $\left(R R=1+\beta_{f} X^{1 / 2}\right)$ model } \\
\hline $1 e-6$ & $7.3 e-9$ & $1.4 \mathrm{e}-9$ & $3.7 e-8$ & $7.0 \mathrm{e}-9$ \\
\hline $10-5$ & $7.3 e-7$ & $1.4 \mathrm{e}-7$ & $3.7 \mathrm{e}-6$ & $7.0 \mathrm{e}-7$ \\
\hline $1 e^{-4}$ & $7.3 e-5$ & $1.4 e-5$ & $3.7 e-4$ & $7.0 \mathrm{e}-5$ \\
\hline $1 e-3$ & $7.3 e-3$ & $1.4 \mathrm{e}-3$ & $3.7 e-2$ & $7.0 \mathrm{e}-3$ \\
\hline \multicolumn{5}{|c|}{ Final square root $\left(R R=1+\beta_{1} X^{1 / 2}\right)$ model } \\
\hline $10-6$ & $4.2 e-9$ & $1.1 \mathrm{e}-9$ & $2.1 \mathrm{e}-8$ & $5.5 e-9$ \\
\hline $1 e-5$ & $4.2 e-7$ & $1.1 \mathrm{e}-7$ & $2.1 \mathrm{e}-6$ & $5.5 \mathrm{e}-7$ \\
\hline $10-4$ & $4.2 \theta-5$ & $1.10-5$ & $2.1 e^{-4}$ & $5.5 e-5$ \\
\hline $1 e-3$ & $4.2 e-3$ & $1.1 e-3$ & $2.2 \mathrm{e}-2$ & $5.5 e-3$ \\
\hline
\end{tabular}

4 The maximum reported SMR/100\% was 13.33. This SMR was based on 2 leukemia deaths among black men from plant 2 with at least 10 years of work (not all of which was salaried) and at least 20 years of elapsed time since hired. (See table 29 of the UAB analysis.) 
corresponding to a 1 in a million excess lifetime risk by linear interpolation ${ }^{5}$ the values would range from 7 to 64 parts per trillion. The "final" model presented in the UAB analysis would yield a corresponding exposure level of 12 parts per trillion.

Table 2. Estimates of the maximum likelihood effective concentration $\left(E_{p}\right)$ and the $95 \%$ lower confidence limit $\left(\mathrm{LEC}_{p}\right)$ of the continuous environmental exposure concentrations associated with varying levels of excess risk (p) from the alternative models.

\begin{tabular}{|c|c|c|c|}
\hline \multirow[t]{2}{*}{ Excess risk $(p)(\%)$} & \multicolumn{2}{|c|}{$\begin{array}{c}\text { 1,3-Butadiene } \\
\text { exposure levels (ppm) }\end{array}$} & \multirow[t]{2}{*}{ Ratio } \\
\hline & $\mathrm{EC}_{\mathrm{p}}$ & $\mathrm{LEC}_{p}$ & \\
\hline \multicolumn{4}{|l|}{ Log-linear model } \\
\hline p $10.0 \%$ & 3.30 & 1.90 & $5.3 e-02$ \\
\hline p $1.0 \%$ & 1.10 & 0.63 & $1.6 \mathrm{e}-02$ \\
\hline p $0.1 \%$ & 0.17 & $9.8 \mathrm{e}-02$ & $1.0 \mathrm{e}-02$ \\
\hline \multicolumn{4}{|l|}{ Power } \\
\hline p $10.0 \%$ & $7.2 \mathrm{e}+03$ & 14 & $7.1 \mathrm{e}-03$ \\
\hline p $1.0 \%$ & 0.53 & $6.3 \mathrm{e}-02$ & 0.16 \\
\hline p $0.1 \%$ & $5.2 \mathrm{e}-03$ & $2.4 \mathrm{e}-03$ & 0.42 \\
\hline \multicolumn{4}{|l|}{ Linear model } \\
\hline p $10.0 \%$ & 12 & 5.50 & $1.8 \mathrm{e}-02$ \\
\hline p $1.0 \%$ & 1.10 & 0.51 & $2.0 \mathrm{e}-02$ \\
\hline p $0.1 \%$ & 0.11 & $5.1 \mathrm{e}-02$ & $2.0 \mathrm{e}-02$ \\
\hline \multicolumn{4}{|l|}{ Square root } \\
\hline$p \nmid 0.0 \%$ & 84 & 16.00 & $6.3 \mathrm{e}-03$ \\
\hline p 1.0\% & 0.74 & 0.14 & $7.10-02$ \\
\hline p $0.1 \%$ & $7.3 \mathrm{e}-03$ & $1.4 \mathrm{e}-03$ & 0.71 \\
\hline \multicolumn{4}{|l|}{ Final square root } \\
\hline p $10.0 \%$ & 49.00 & 13.00 & $7.7 e-03$ \\
\hline p $1.0 \%$ & 0.43 & 0.11 & $9.1 e-02$ \\
\hline p $0.1 \%$ & $4.2 \mathrm{e}-03$ & $1.1 e-03$ & 0.91 \\
\hline
\end{tabular}

a The ratio is the excess risk $(\mathrm{p} / 100 \%)$ divided by the one-sided lower $95 \%$ confidence limit of the exposure estimate (LEC $\mathrm{L}_{\mathrm{p}}$ ).

\section{Comparison of results with previously derived estimates of risk}

It is informative to compare the results from this analysis with those that were previously developed by the National Institute for Occupational Safety and Health (NIOSH) (9) using the NTP mouse bioassay (21). Lifetime estimates of risk for occupational exposures from the analysis based on the NTP bioassay are presented in table 3. For comparative purposes, the risk estimates for leukemia mortality from the models that produced the highest (final square root model) and the lowest risks (log-linear model) from the UAB analysis are also presented in table 3 . The analysis of the NTP mouse bioassay presented estimates of risk for both men and women and for several cancer sites that were observed to be significantly elevated. Some of the cancer sites (eg, forestomach and harderian gland) observed in the mouse bioassay are of questionable relevance to humans. Probably, the most relevant comparison was with lymphocytic lymphoma in mice, since these tumors are of lymphopoietic origin, as are the major tumor types observed in human studies (ie, leukemia and lymphosarcoma). The results from our analysis of the NTP bioassay for $1 \mathrm{ppm}$ (current OSHA standard) ranged from 1 (males) to 9 (females) per 1000 ; in comparison, the estimates of excess risk for leukemia derived from the epidemiologic study range from 1 to 8 per 1000 workers. Thus the excess risk estimates from these epidemiologic and toxicologic analyses are almost identical for tumors of hematopoietic origin at current occupational exposure levels to BD. It should be noted that chemical carcinogens are not always

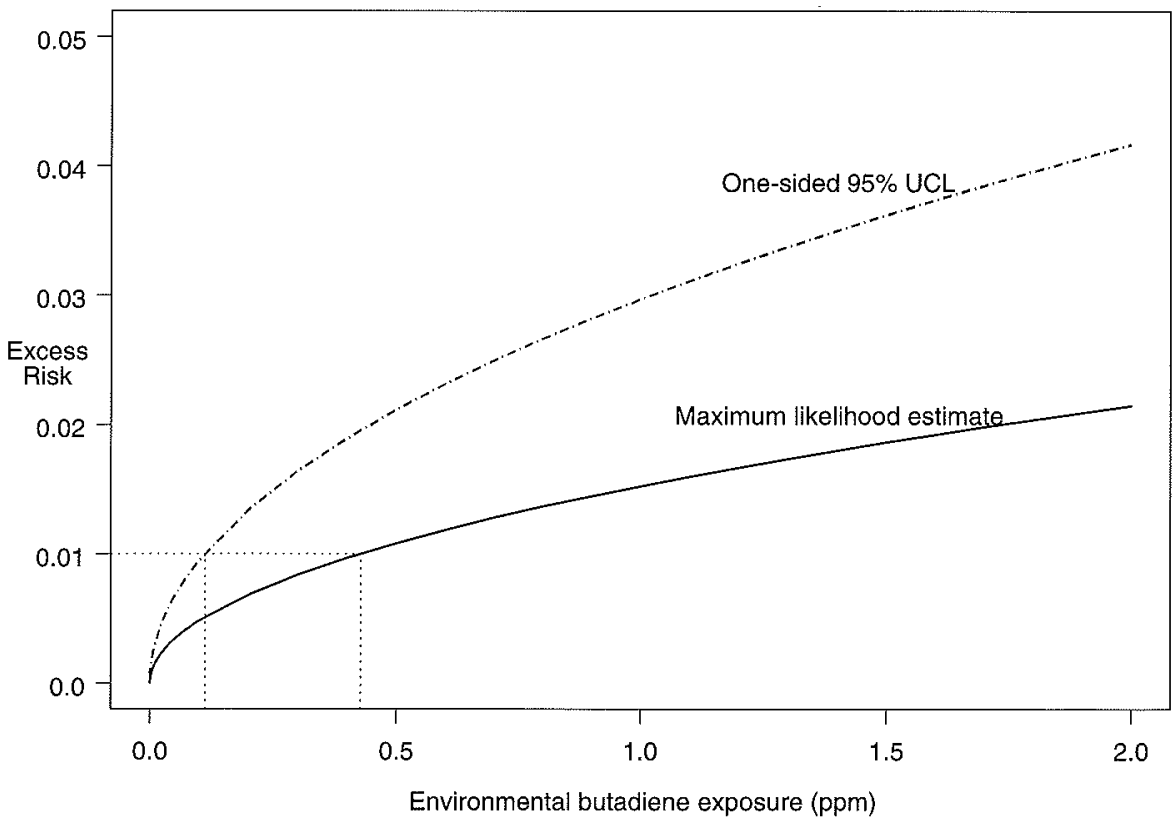

Figure 3. Environmental risk and $95 \%$ upper confidence limits based on the final square root model. (UCL = upper confidence limit)

5 Linear interpolation between the origin and the point $\left(\mathrm{LEC}_{\mathrm{p}}, \mathrm{p}\right)$ is also referred to as "linear extrapolation." 
expected to produce tumors at identical sites in animals and humans. Using the results from all of the tumor sites in the mouse bioassay would yield a much wider range of risk estimates for a 1-ppm exposure ranging from 3 per million to 3 per hundred for a 1-ppm exposure.

\section{Discussion}

The use of animal bioassay studies for predicting cancer risks in humans has been, and will most likely continue to be, a source of scientific controversy. Several investigators have explored the concordance between the risk estimates derived from animal bioassay studies with those developed from epidemiologic studies in which both sources of information exist (22-24). These analyses have generally found a relatively high degree of concordance, with some notable exceptions. It would appear that the case of BD provides another example of good agreement between predictions based on animal bioassays and epidemiologic data.

The results from the epidemiologic risk analysis presented in this paper also suggest that the quantitative estimates of risk that were previously derived from our analysis of the NTP mouse bioassay study were not "exaggerated" as was previously suggested (8). In fact, at the current OSHA standard of $1 \mathrm{ppm}$ the leukemia-risk estimates derived from this epidemiologic analysis are remarkably similar to those that we previously developed for our analysis of the NTP mouse bioassay results for lymphocytic lymphoma.

At the very least, the recent findings by Delzell et al (25-28) provide strong qualitative evidence supporting the concern generated by the NTP bioassay with respect to a significant risk of cancer from occupational exposure to BD. This concern is also supported by the results from the demonstration of an increase in leukemia or other lymphopoietic neoplasms in other epidemiologic studies of BD-exposed workers.

It should be noted that our 1993 risk assessment for BD made use of the inhaled dose of BD as a dose metric. Since that time 2 physiologically-based pharmacokinetic models have been published which incorporate in vitro data on the metabolism of BD in humans (29, 30 ). These models represent an effort to improve the risk assessment process for BD by utilizing scientific data rather than generic assumptions regarding interspecies scaling. At this point we have not examined the degree to which the use of these models would alter our risk estimates for $\mathrm{BD}$.

\section{Sources of uncertainty}

As with any risk assessment, there are several assumptions and sources of uncertainty that need to be clearly
Table 3. Comparison of the maximum likelihood estimates of lifetime excess risk due to 45 years of occupational exposure to 1,3butadiene, using the toxicologic and epidemiologic data. (TWA = time-weighted average)

\begin{tabular}{lllll}
\hline & \multicolumn{4}{c}{$\begin{array}{c}\text { Lifetime excess risk } \\
\text { (8-hour TWA concentration) }\end{array}$} \\
\cline { 2 - 5 } & $0.5 \mathrm{ppm}$ & $1 \mathrm{ppm}$ & $2 \mathrm{ppm}$ & $5 \mathrm{ppm}$ \\
\cline { 2 - 5 } & & & \\
Epidemiologic data for leukemia & & & \\
Final square root & $4.8 \mathrm{e}-3$ & $6.8 \mathrm{e}-3$ & $9.6 \mathrm{e}-3$ & $1.5 \mathrm{e}-2$ \\
Multiplicative & $5.6 \mathrm{e}-4$ & $1.2 \mathrm{e}-3$ & $2.6 \mathrm{e}-3$ & $8.5 \mathrm{e}-3$ \\
Data from male mice & & & & \\
$\quad$ Forestomach & $8 \mathrm{e}-6$ & $3 \mathrm{e}-5$ & $1 \mathrm{e}-4$ & $8 \mathrm{e}-4$ \\
Harderian gland & $7 \mathrm{e}-3$ & $1 \mathrm{e}-2$ & $3 \mathrm{e}-2$ & $7 \mathrm{e}-2$ \\
Heart hemangiosarcoma & $1 \mathrm{e}-4$ & $5 \mathrm{e}-4$ & $2 \mathrm{e}-3$ & $1 \mathrm{e}-2$ \\
Histiocytic sarcoma & $4 \mathrm{e}-3$ & $8 \mathrm{e}-3$ & $2 \mathrm{e}-2$ & $4 \mathrm{e}-2$ \\
Liver & $2 \mathrm{e}-3$ & $4 \mathrm{e}-3$ & $7 \mathrm{e}-3$ & $2 \mathrm{e}-2$ \\
Lymphocytic lymphoma & $4 \mathrm{e}-4$ & $9 \mathrm{e}-4$ & $2 \mathrm{e}-3$ & $4 \mathrm{e}-3$ \\
Lung & $6 \mathrm{e}-3$ & $1 \mathrm{e}-2$ & $2 \mathrm{e}-2$ & $6 \mathrm{e}-2$ \\
Data from female mice & & & & \\
Forestomach & $3 \mathrm{e}-3$ & $5 \mathrm{e}-3$ & $1 \mathrm{e}-2$ & $2 \mathrm{e}-2$ \\
Harderian gland & $4 \mathrm{e}-3$ & $7 \mathrm{e}-3$ & $1 \mathrm{e}-2$ & $3 \mathrm{e}-2$ \\
Heart hemangiosarcoma & $4 \mathrm{e}-7$ & $3 \mathrm{e}-6$ & $2 \mathrm{e}-5$ & $4 \mathrm{e}-4$ \\
Histiocytic sarcoma & $6 \mathrm{e}-3$ & $1 \mathrm{e}-2$ & $2 \mathrm{e}-2$ & $6 \mathrm{e}-2$ \\
Liver & $3 \mathrm{e}-3$ & $7 \mathrm{e}-3$ & $1 \mathrm{e}-2$ & $3 \mathrm{e}-2$ \\
Lymphocytic lymphoma & $4 \mathrm{e}-3$ & $9 \mathrm{e}-3$ & $2 \mathrm{e}-2$ & $4 \mathrm{e}-2$ \\
Lung & $2 \mathrm{e}-2$ & $3 \mathrm{e}-2$ & $6 \mathrm{e}-2$ & 0.1 \\
Mammary gland & $2 \mathrm{e}-3$ & $4 \mathrm{e}-3$ & $7 \mathrm{e}-3$ & $2 \mathrm{e}-2$ \\
Ovary & $4 \mathrm{e}-3$ & $9 \mathrm{e}-3$ & $2 \mathrm{e}-2$ & $4 \mathrm{e}-2$ \\
\hline
\end{tabular}

recognized. One critical source of uncertainty is the validity of the statistical models used. The UAB analysis included analyses of residuals and of influential data points, which did not indicate any problems with their models. The Pearson chi-square test $(\mathrm{P}=0.93)$ and the deviance in their final model did not suggest a lack of fit to the data. Thus their models appeared to be appropriate according to classical statistical criteria. Since the difference in deviance between the alternative models was small, it is difficult to choose 1 model over another for the analysis as the "best" model. The findings from our analysis suggest that estimates of risk are not highly model dependent for occupational exposures of current concern. However, estimates of risk for environmental exposures (eg, at 1 in a million risk level) were found to be highly dependent on the model chosen. On the other hand, the results were not found to be highly model dependent when an approach based on the effective dose $\left(\mathrm{EC}_{\mathrm{p}}\right)$ was used, as proposed in the new EPA cancer guidelines (17), particularly when a $1 \%$ risk (p) criterion was used.

The other major source of uncertainty in this analysis is the potential for misclassification of exposures in the UAB analysis. This is a frequent limitation of nearly all epidemiologic studies of this type for quantitative risk assessment purposes. The exposures of this study were based on the modeling of a relatively extensive set of data. However, questions have been raised concerning the accuracy of exposure estimates particularly for some 
ill-defined tasks. For example, the work histories of the maintenance laborers did not indicate whether they were vessel cleaners (a high-exposure category) or building cleaners (a low-exposure category). Researchers at the $\mathrm{UAB}$ are currently working on a reevaluation of the exposure estimates used in their study.

Another concern that has been expressed is regarding the assignment of peak exposures, defined as average exposures equal to or greater than 100 ppm over 15 minutes, in the analysis. Additional analyses concerning peak exposures have been conducted by the UAB researchers (Delzell E, Macaluso M, Lally C, Cole P. Mortality study of synthetic rubber workers: additional analyses of data on monomer peaks and employment in certain work areas. Report submitted to the International Institute of Synthetic Rubber Producers, October 16, 1996). Peak exposures were defined for these analyses as any exposure that occurred that was $>100$ (BD100) or 500 (BD500) ppm. A weak but positive association was observed between leukemia and the BD100 peak exposures. However, there was no evidence of a dose-response relationship for the peak exposures when cumulative exposure was controlled for in the analysis. The investigators concluded that their analysis did not provide a firm basis for distinguishing between the importance of $\mathrm{BD}$ ppm-years and BD peaks as a cause of leukemia.

Finally, there is the possibility that the excess leukemia observed in the UAB study was related to confounding from another chemical that was also used at the plant. Initially, the analyses conducted by the UAB researchers considered potential confounding by benzene and styrene. Benzene was only weakly associated with leukemia in the analysis, and the effect of benzene was eliminated when the analysis was controlled for BD and styrene (14). Leukemia mortality did appear to increase as the styrene exposure levels increased, although not as strongly and as consistently as for the BD exposure. Studies of workers exposed to styrene alone have not demonstrated an increased risk of leukemia $(31-35)$. Thus it appears highly unlikely that either benzene or styrene exposure was a significant confounder in this study. It has recently been suggested that exposure to dithiocarbamates may have potentially confounded the observed association between BD exposure and leukemia in the study by Delzell et al (36). Dithiocarbamates have been shown to be hematoxic and immunotoxic, but they have not been associated with leukemia risk in animals or humans.

There are also several areas of uncertainty in the comparisons of the carcinogenicity of BD in animals and humans, for example, the choice of which tumors sites to use for the comparison, the choice of statistical models, the manner in which dose is measured in the model, and the method of animal-to-human extrapolation. Our mouse-to-human comparison has focused primarily on tumors of hematopoietic origin, although numerous other tumor types have been observed in the mouse. Although we believe that this a reasonable choice, it must be recognized that the results from modeling the other tumor sites observed to be in excess in mice produced a wide range of risk estimates. For example, at occupational exposures of $1 \mathrm{ppm}$ the estimates of excess risk ranged from 3 per million to 1 per 100 , which is over 4 orders of magnitude. The more extreme estimates of risk were for tumor sites that do not occur in humans (ie, forestomach and heart hemangiosarcoma).

Our analyses of the mouse bioassay data for BD was limited to a single class of statistical models (ie, multistage Weibull time-to-tumor models). The BD dose was measured in terms of the inhaled concentration of BD, as opposed to, say, the concentration of BD or a BD metabolite at the site of tumor origin. Mouse-to-human extrapolation was based of the assumed equivalency of doses expressed as $\mathrm{mg} / \mathrm{kg}^{3 / 4}$-day. It should be recognized that analyses based on different statistical models, dose metrics, methods of species extrapolation, and assumptions regarding tumor site concordance would probably yield somewhat different results.

\section{Concluding remarks}

The finding of a highly significant exposure-response relationship between $\mathrm{BD}$ exposure and leukemia in the $\mathrm{UAB}$ analysis certainly provides substantial support for the concerns over human cancer risk that were previously raised by the NTP mouse bioassay studies. The similarity of the risk estimates derived from models of the mouse bioassay study for lymphocytic lymphoma and the epidemiologic data for leukemia for the occupational exposures of concern provides some support for the continued modeling of animal bioassay data for predicting risks. On the other hand, the estimation of risks for exposure levels of environmental concern were found to be highly model dependent when either the epidemiologic or toxicologic data were used. This is not a surprising result, since one would expect the predictions from these models to be highly model dependent when extrapolation is made well beyond the range of the observed data. The results from using a procedure based on the estimation of an effective dose (EC), as proposed by the new EPA cancer guidelines, is far less model dependent, and this lack of dependency is an attractive feature of this alternative approach.

Clearly there have been, and will be, situations in which the results from toxicologic studies may not produce reliable estimates of human cancer risks. On the other hand, it is possible that several calamitous human exposures to toxic agents could have been prevented had the proper toxicologic tests been conducted and the proper regulatory policies been set (7). We believe that BD represents an example that supports the prudence of past 
US policies that have relied on animal bioassay studies for developing regulatory standards rather than waiting for epidemiologic studies to detect the tragic effects of carcinogenic exposures on workers or other exposed human populations. Additional comparative analyses of this kind are needed to permit a systematic evaluation of the concordance between the predictions from toxicologic and epidemiologic risk assessment models.

\section{Acknowledgments}

The authors would like to thank Drs Peter Infante, Ron Melnick and Elizabeth Ward for their insightful comments on earlier drafts of this paper.

\section{References}

1. Ames BN, Gold LS. Chemical carcinogenesis: too many rodent carcinogens. Proc Natl Acad Sci 1990;87:7772-6.

2. Ames BN, Gold LS. Too many rodent carcinogens: mitogenesis increases mutagenesis. Science 1990;249:970-1.

3. Ames BN, Gold LS. Letter to the Editor on carcinogens and human health (part 1). Science 1990;250:1645-6.

4. Abelson PH. Testing for carcinogens with rodents. Science 1990;249:1357.

5. Perera, FP. Letter to the Editor on carcinogens and human health (part 1). Science 1990;250:1644-5.

6. Rall, DP. Letter to the Editor on carcinogens and human health (part 2). Science 1991;251:10-12.

7. Zbinden G. Predictive value of animal studies in toxicology. Regul Toxicol Pharmacol 1991;14:167-77.

8. Abelson PH. Exaggerated carcinogenicity of chemicals. Science 1992;256:1609.

9. Dankovic DA, Smith RJ, Stayner LT, Bailer AJ. Letter to the Editor on carcinogenicity of butadiene. Science 1992; 257:1330.

10. Landrigan PJ. Letter to the Editor on carcinogenicity of butadiene. Science 1992;257:1330

11. Rall DP. Letter to the Editor on carcinogenicity of butadiene. Science 1992;257:1330.

12. Melnick RL, Kohn MC. Mechanistic data indicate that 1,3butadiene is a human carcinogen. Carcinogenesis 1995; 16:157-63.

13. Delzell E, Sathiakumar N, Hovinga M. A followup study of synthetic rubber workers. Toxicology, 1996;113:182-9.

14. Macaluso M, Larson R, Delzell E, Sathiakumar N, Hovinga M, Juliam Jim, et al. Leukemia and cumulative exposure to butadiene, styrene and benzene among workers in the synthetic rubber industry. Toxicology 1996;113:190-202.

15. Frome EL, Checkoway H. Use of Poisson regression models in estimating incidence rates and ratios. Am J Epidemiol 1985;121(2):309-22.

16. National Center for Health Statistics. Vital statistics of the United States 1989, vol II (Mortality). Washington (DC): US Government Printing Office, 1993. DHHS publication, no (PHS) 93-1101.

17. US Environmental Protection Agency. Proposed guidelines for carcinogenic risk assessment. Fed Reg 1996;61 (79): 17960 - 8011.

18. Dankovic DA, Smith RJ, Stayner LT, Bailer AJ. Butadiene and styrene: assessment of health hazards. Sorsa M, Peltonen $\mathrm{K}$, Vanio H, Hemminki K, editors. Lyon: International Agency for Research on Cancer, 1993:335-44. IARC scientific publications no 127.

19. Infante PF. Cancer and blue collar workers: who cares? Sci Solutions 1995;5:52-57.

20. Occupational Safety and Health Administration. Fed Reg 1996;61(Nov 4):56746-856.

21. Melnick RL, Huff J, Chou BJ, Miller R. Carcinogenicity of 1,3-butadiene in $\mathrm{B} 6 \mathrm{C} 3 \mathrm{~F} 1$ mice at low exposure concentrations. Cancer Res 1990;50:6592-9.

22. Allen BC, Crump KS, Shipp AM. Correlation between carcinogenic potency of chemicals in animals and humans. Risk Anal 1988;8(4):531-57.

23. Zeiss L. Assessment of carcinogenic risks in the workplace, In: chemical risk assessment and occupational health: current applications, limitations and future prospects. Smith $\mathrm{CM}$, Christiani DC, Kelsey KT, editors. Westport (CT): Auburn House, 1994

24. Stayner LT, Bailer AJ. Comparing toxicologic and epidemiologic studies: methylene chloride a case study. Risk Anal 1993;13(6):667-73

25. Ward EM, Fajen JM, Ruder AM, Rinsky RA, Halperin WE, Fessler-Flesch C. Mortality study of workers employed in 1,3-butadiene production units from a large chemical workers cohort. Environ Health Perspect 1995;103:598-603.

26. Divine BJ, Hartman CM. Mortality update of butadiene production workers. Toxicology 1996;113:190-202.

27. Matanoski G, Francis M, Correa-Villasenor A, Elliott E, et al Cancer epidemiology among styrene-butadiene rubber workers. Lyon: International Agency for Research on Cancer (IARC), 1993:363-74. IARC scientific publication no 127.

28. Meinhardt TJ, Lemen RA, Crandall MS, Young RJ. Environmental epidemiologic investigation of the styrene-butadiene rubber industry: mortality patterns with discussion of the hematopoietic and lymphatic neoplasms. Scand J Work Environ Health 1982:8:250—9.

29. Kohn MC, Melnick RL. Species differences in the production and clearance of 1,3-butadiene metabolites: a mechanistic model indicates predominantly physiological, not biochemical, control. Carcinogenesis 1993;14:619-28.

30. Medinsky MA, Leavens TL, Csanady. In vivo metabolism of butadiene by mice and rats: a comparison of physiological model predictions and experimental data. Carcinogenesis 1994;15:1329-40.

31. Bond GG, Bodner KM, Olsen GW, Cook RR. Mortality among workers engaged in the development or manufacture of styrene-based products: an update. Scand J Work Environ Health 1992;18:145-54.

32. Okun AH, Beaumont JJ, Meinhardt TJ, Crandall MS. Mortality patterns among styrene-exposed boat builders. Am J Ind Med 1985;8:193-205.

33. Wong O. A cohort mortality study and case-control study of workers potentially exposed to styrene in the reinforced plastics and composites industry. Br J Ind Med 1990;47:743-62.

34. Frentzel-Beyme R, Thiess AM, Wieland R. Survey of mortality among employees engaged in the manufacture of styrene and polystyrene at the BASF Ludwigshafen works. Scand J Work Environ Health 1978;4 suppl 2:231-9.

35. Kogevinas M, Ferro G, Saracci R, Andersen A, Biocca M, Coggon D, et al. Cancer mortality in an international cohort of 
workers exposed to styrene. In: Sorsa M, Peltonen K, Vainio $\mathrm{H}$, Hemminki $\mathrm{K}$, editors. Butadiene and styrene: assessment of hazards. Lyon: International Agency for Research on Cancer (IARC), 1993:289—90. IARC scientific publications, no 127.
36. Irons RD, Pyatt DW. Dithiocarbamates as potential confounders in butadiene epidemiology. Carcinogenesis 1998;1 $9(4): 539-42$.

Received for publication: 18 June 1999 